\title{
A First Throw of the Stone: A Pilot of Redesigned Co-op Work Term REQUIREMENTS AT THE UNIVERSITY OF VICTORIA
}

\author{
Margaret Gwyn ${ }^{1}$, Joel B. Frey ${ }^{2}$, and Leo Spalteholz ${ }^{1}$ \\ ${ }^{1}$ Univeristy of Victoria, ${ }^{2}$ University of Saskatchewan \\ mgwyn@uvic.ca,joel.frey@usask.ca, leos@uvic.ca
}

\begin{abstract}
This paper describes the progress made over the past year on UVic's project to redesign their co-op work term requirements. The new requirements are intended to increase the amount of instruction and assessment of higher-level Graduate Attributes in the program, to improve student engagement with and performance on work term requirement, and to replace a final year technical writing course that does not seem to be achieving its intended outcomes.

A pilot of the one component of this project will run from May-August 2019. In this paper we will describe the material that has been developed for the pilot. We will also discuss the process by which the material was developed and the details of organizing the pilot.
\end{abstract}

Keywords: Graduate attributes, Co-operative education, Technical writing, On-line learning, Impact of engineering, Lifelong learning

\section{INTRODUCTION}

In 2018, the Faculty of Engineering at the University of Victoria proposed a redesign of the Co-operative Education (co-op) work term requirements of their program [7]. In three of their four mandatory work terms, instead of writing a typical work term report, students would complete a series of activities related to communication, life-long learning, and at least one other higher-level graduate attribute (GA): professionalism, impact of engineering on society and the environment, ethics and equity, or economics and project management.

In the remaining mandatory work term, students would still complete activities related to life-long learning, but would use the rest of their time to focus on the writing of a technical recommendation report. The communication exercises in previous work terms would be sequentially "laddered" to prepare students to write this report, and instructional activities and formative assessment over the term would help ensure the production of quality work.

This proposal was developed by a project team comprised of the Associate Dean Undergraduate Programs, the Program Manager of the Engineering and Computer Science Co-op and Career Program, the chair of our Mechanical Engineering Department, the Accreditation
Analyst and a project consultant. The goal of the redesign is three-fold: to add more instruction and assessment of higher-level GAs to our programs; to provide students with more pedagogically valuable work term requirements, thereby hopefully improving their engagement and performance; and to replace a final year technical writing course that does not seem to be effectively preparing students to write workplace-quality reports.

Since the publication of our last paper, much progress has been made on this project. Funding was secured to develop a first portion of the redesign, one term's worth of material, representing approximately one-quarter of the full project. A pilot offering of this material will run from May - August 2019.

In this paper we will chronicle the developments that have taken place since our last paper, including the process by which the pilot course was developed. We will describe the activities that make up the course and our motivation for choosing these specific exercises. We will recount the details of organizing the pilot, discuss our plans to assess its results, and outline the next steps for the project.

Based on the reaction to our first paper, many schools are interested in revamping their co-op work term requirements and/or finding novel ways to teach and assess the higher-level GAs. We hope this information will be useful to other institutions, and look forward to the valuable feedback sure to come from our colleagues.

\section{COURSE DEVELOPMENT}

In this section, we describe the development that has taken place since our previous paper.

In May 2018, the project team met again with the Dean of our faculty, mainly to discuss how to fund the project. The Dean ultimately suggested we pursue "piecemeal" funding to get the project started, rather than delaying until funding for the full project was secured. The Dean also invited the team to present the project at a faculty Executive Council meeting. The members of the Executive Council were very positively inclined towards the idea, and expressed their desire to implement the project as soon as possible.

Over June and July, the consultant met with a focus group of students selected from each of our engineering 
programs to present the proposed project. The students were generally in support of the proposal, including the idea of moving away from the current pass/fail grading of work terms. They suggested emphasizing the links to the licensure requirements of Engineers and Geoscientists of British Columbia (EGBC), and that the skills developed in the new model are in demand by employers. The project team also discussed if input from co-op employers was needed at this stage; ultimately we decided it was not.

Two other important events happened in June and July: first, the chair of our Mechanical Engineering Department, a member of the project team, took on the role of Acting Dean. His appointment, originally for six months, was later extended to 30 June 2020. This fortunate event assured us consistent and engaged support for the duration of the course development and pilot offering.

Second, a one-time source of funding was identified that would allow us to develop one of the four courses that make up the whole project. With this secured, the consultant met with UVic's Technology Integrated Learning office (TIL) to describe the project and discus what support they might be able to offer. TIL agreed to provide course development services free of charge for the first course of the project.

In August, our consultant announced that he would be leaving the university for a position elsewhere. Rather than add a new person to the team, we decided to have the Accreditation Analyst take on project management duties.

With funding, technical support and project management in place, it was now time to find a person who could serve as a subject matter expert (SME) in one of the higher-level GAs. Over the summer, the project team had approached people with expertise in various GAs, but was unable to find anyone who could participate.

The team decided to pick a specific GA and more widely advertise our search for SME. After much discussion, GA \#9, "the impact of engineering on society and the environment", was chosen. The team felt that content related to professionalism, ethics and equity might already be available from EGBC, and that our programs were more lacking in material related GA \#9 than they were in economics and project management.

An advertisement for an SME was circulated in late August through the Graduate Attribute Professional Network mailing list [5]. The team also planned to advertise through the CEEA-ACEG newsletter, but this ultimately wasn't possible given the timelines that were involved. A number of excellent candidates applied for the position, and by mid-September, an impact of engineering SME had been hired.

Also by mid-September, the co-op Program Manager identified a team of four co-op coordinators who would serve as co-op SMEs for the course development. Our course development team now consisted of a learning experience designer from TIL, the impact of engineering
SME, the co-op SME team, and the Accreditation Analyst, serving as project manager.

The first four months of course development (September - December 2018) were focused on creating a course "blueprint". The blueprint is a tool that acts as an outline for a course, and encourages learner-centered development: starting with learning outcomes, developing assessments next, and designing assignments last [10]. The course development team was guided through this process by the learning experience designer. Her expertise was invaluable; other institutions who are considering similar projects are strongly urged to seek out the services of their institutions' learning and teaching centres.

As the blueprinting process progressed, the course development team realized writing exercises need to be part of the course. To facilitate their creation, two technical writing SMEs from the Department of English joined our team. These individuals are the course coordinators for the technical writing portion of the two first-year design courses all UVic engineering students must complete. Their participation helped ensure the writing assignments would build on what the students had already learned.

Given the size of the course development team, most work on the course was done in a modular fashion: different sections of the blueprint would be assigned to different groups by the learning experience designer. Periodic whole-group meetings kept the project coordinated. These meetings were held as teleconferences, as both the impact of engineering SME and one of the coop SMEs were based outside of Victoria. Throughout the process, the Accreditation Analyst provided updates to the original project team and members of the faculty's accreditation committee.

In early December, our impact of engineering SME visited campus for a two-day intensive work session. From 9 am $-4: 30 \mathrm{pm}$ each day, the learning experience designer and one of her colleagues from TIL guided the whole team through discussions and exercises to fully flesh out the course blueprint. This process greatly accelerated the development of the blueprint and was very valuable.

Over the January - April term, the team worked to create content for the course, based on the design laid out in the course blueprint. Again, work was done in a modular fashion, coordinated by the learning experience designer and the project manager. The content was incorporated into a course shell in UVic's learning management system (LMS) CourseSpaces, a version of Moodle. This work was done by the learning experience designer; again, her expertise was crucial to the creation of the course.

\section{COURSE MATERIAL}

In this section, we describe the material that was developed for the Summer 2019 pilot course offering. This material was designed to achieve the course's learning 
outcomes (LOs), as developed during the blueprinting process:

1. Critically reflect on your personal and professional growth during the work term in relation to your work experience, course content, values, and goals to identify next steps in your personal or professional learning plan.

2. Identify the impact of the engineering profession on society and the environment and the roles of social responsibility \& professional ethics therein.

3. Identify and analyze the legal, economic, environmental, cultural, social, and health and safety issues relevant to a professional engineer's role in society.

4. Recognize the responsibility for environmental stewardship inherent within the profession of engineering.

5. Evaluate the role of professional engineers in the economic, social, and environment aspects of sustainable development and design.

6. Employ professional communication practices appropriate to the context of the discipline, task, and audience.

The material consists of a series of assignments the students will complete over the term. These assignments are shown in Table 1, organized by the category into which each assignment falls and its related $\mathrm{LO}(\mathrm{s})$. We also show the due date of each assignment, our estimate the time required to complete it, the weight of the assignment in the overall course, and who will be responsible for marking it.

As discussed in our earlier paper, co-op work terms at UVic are currently graded on a pass/fail basis. Assigning a numeric grade would require approval from Senate committees. The project team decided not to pursue this process before the pilot offering of the course. However, during the pilot, a numeric grade will be calculated for each student based on the weights in Table 1. This grade will appear on a certificate of completion signed by the Associate Dean Undergraduate Programs that the students can choose to download at the end of the course. We hope this will provide at least some motivation to the students to engage more fully with the course requirements.

We now describe the assignments in each category.

\subsection{Competency Assessment}

The first category of assignments is made up of the three parts of the competency assessment. As discussed in our first paper, competency assessment is already a part of every work term at UVic. Students must self-assess their current proficiency in a set of institution-defined competencies at the beginning of each work term. They choose a few they wish to develop over the term and write learning objectives for themselves. They again self-assess at the midterm and describe their progress on their goals. Finally, at the end of term, they self-assess once more, and reflect on and assess how they met their objectives.

The course development team needed to make only a few small changes to this activity to strengthen its connection to GA \#12, life-long learning. At the beginning of term, students are asked to do one additional thing: explain their choice of competencies for development. This provides a measure of their ability to identify gaps in their knowledge, an important aspect of life-long learning.

Throughout the rest of the activity, the instructions to students about how to set their goals, choose their strategies, and assess their progress were made more explicit, to encourage students to engage more fully and reflect more deeply on the activity. Rubrics were also developed by the co-op SME team and the Accreditation Analyst to allow for easy assessment of the various parts of the process. These rubrics, like all rubrics in the course, are made available to students to help them better understand what is expected of them.

Table 1: Pilot course assignments

\begin{tabular}{|c|c|c|c|c|c|}
\hline Category / LO & Assessment & Due date & $\begin{array}{l}\text { Est. time } \\
\text { req'd }\end{array}$ & Weight & Marker \\
\hline \multirow{3}{*}{$\begin{array}{l}\text { Competency Assessment } \\
(\mathrm{LO} \# 1)\end{array}$} & Competency Assessment Part 1 & May 24 & $1 \mathrm{hr}$ & $7 \%$ & WSV Coord. \\
\hline & Competency Assessment Part 2 & July 5 & $1 \mathrm{hr}$ & - not marked & WSV Coord. \\
\hline & Competency Assessment Part 3 & Aug 16 & $1 \mathrm{hr}$ & $8 \%$ & WSV Coord. \\
\hline \multirow[t]{3}{*}{ Learning Plan (LO \#2) } & Learning Plan $\mid$ Part 1 & June 7 & $1 \mathrm{hr}$ & $8 \%$ & WSV Coord. \\
\hline & \begin{tabular}{|l|l} 
Learning Plan & Part 2
\end{tabular} & July 26 & $1-3 \mathrm{hrs}$ & $4 \%$ & WSV Coord. \\
\hline & \begin{tabular}{|l|l} 
Learning Plan & Part 3 \\
\end{tabular} & Aug16 & $1-3 \mathrm{hrs}$ & $13 \%$ & WSV Coord. \\
\hline \multirow{7}{*}{$\begin{array}{l}\text { Impact of Engineering units } \\
(\mathrm{LO} \# 3,4,5)\end{array}$} & \begin{tabular}{l|l} 
Unit 1 & Health and Safety
\end{tabular} & May 24 & $1 \mathrm{hr} 50 \mathrm{~min}$ & $4 \%$ & Course TA \\
\hline & \begin{tabular}{|l|l|} 
Unit 2 & Economy \\
\end{tabular} & May 31 & $1 \mathrm{hr} 50 \mathrm{~min}$ & $4 \%$ & Course TA \\
\hline & \begin{tabular}{l|l} 
Unit 3 & Law \\
\end{tabular} & June 14 & $2 \mathrm{hr} 10 \mathrm{~min}$ & $4 \%$ & Course TA \\
\hline & \begin{tabular}{l|l} 
Unit 4 & Culture \\
\end{tabular} & June 21 & $3 \mathrm{hr} 50 \mathrm{~min}$ & $4 \%$ & Course TA \\
\hline & \begin{tabular}{l|l} 
Unit 5 & Environment \\
\end{tabular} & July 5 & $2 \mathrm{hr} 20 \mathrm{~min}$ & $4 \%$ & Course TA \\
\hline & \begin{tabular}{l|l} 
Unit 6 & Sustainability \\
\end{tabular} & July 12 & $3 \mathrm{hrs} 30 \mathrm{~min}$ & $4 \%$ & Course TA \\
\hline & $\begin{array}{l}\text { Unit discussion contributions } \\
\text { (x2) }\end{array}$ & $\begin{array}{c}\text { - same as } \\
\text { associated unit }\end{array}$ & $\begin{array}{l}\text { - included in } \\
\text { unit estimate }\end{array}$ & $12 \%$ & Course TA \\
\hline \multirow{2}{*}{$\begin{array}{l}\text { Writing assignments (LO } \\
\# 6 \text { ) }\end{array}$} & Stakeholder Engagement Memo & June 28 & $1-3 \mathrm{hrs}$ & $12 \%$ & Course TA \\
\hline & Problem Definition & July 19 & $1-3 \mathrm{hrs}$ & $12 \%$ & Course TA \\
\hline
\end{tabular}




\subsection{Learning Plan}

The second category of assignments consists of the three-part learning plan exercise. This exercise guides students through learning about their work preferences, finding information about careers of interest, and creating a plan for their final terms at university and entry into the work force.

The motivation for this assignment is a desire to improve post-graduation employment rates for engineering students. The Ontario Society of Professional Engineers (OSPE) found that based on 2011 census data, only about $30 \%$ of engineering degree holders work in engineering or engineering management jobs [6]. Another third work in areas that require a degree of some sort, and a full third work in areas that do not necessarily require a degree at all. Data from British Columbia indicates a nearly identical split. This finding seems to conflict with the common knowledge that engineering degrees are in demand and the fact that the engineering industry is facing labour shortages [9]. The OSPE identifies participation in co-op as a key factor for improving post-graduate employment rates, an advantage that UVic has exploited for 35 years with a mandatory co-op program in all engineering disciplines. However, can we improve outcomes further than simply requiring participation in co-op?

One key advantage of a co-op program is to allow students to narrow down what they want to do by prototyping various jobs. However, most students do not take an intentional approach to this. Students are glad to land their first co-op positions and are often less concerned - at least at first - about what kind of position it is. The least-effort solution to satisfying UVic's four work term requirement is to return to previous employers, a prospect to which students who are less confident in their abilities or competitiveness may be attracted. High performing students are often asked to return to their previous employers as well, and even though those positions may be high quality, students could graduate without having taken advantage of the chance to try a range of roles. Although students do have an instinct and drive to try "something different", they often do not examine what "different" experience they are looking for, or how to take a structured approach to finding it. We theorize that one reason behind the low percentage of engineering graduates working in engineering may be that they have not found a satisfying fit for themselves in their discipline and end up disillusioned.

Students generally either do not know what they want to do, or only know it with very poor definition. They may want to be a civil engineer and have a vague idea they want to get involved in constructing buildings, but what does that mean day-to-day? Do they actually want to sit at a desk all day and design structural members using 3D modelling software? Do they want to be on-site solving complex problems during the execution of large building projects? Do they want to research how to drive down the cost of building through automation? Do they want to travel to remote communities to solve housing challenges using local expertise? The learning plan exercise is designed to encourage the introspection and reflection required to answer these questions.

To encourage a more proactive exploratory and planning approach in students, the co-op SME team was heavily inspired by the book "Designing Your Life" [2]. Based on their undergraduate course at Stanford, Burnett and Evans teach how to use design thinking and tools like prototyping to design a well-lived, joyful life. Before getting into the "what" students want to do, the first part of the Learning Plan - based on the Good Time Journal in Designing Your Life - asks students to dig into the "how" of the work. Through a two-week journaling exercise, students note the tasks they are engaged in, and rate them based on their level of engagement and impact on their energy levels (energizing or draining). Following the logging exercise, students characterize the most and least engaging activities, and then write a reflection on their insights about how they like to work from the exercise. Students are encouraged to explore how their reaction to individual tasks generalizes to the characteristics of the work, and conduct an informal root cause analysis behind those reactions. For example, for an un-engaging or draining activity, is the root cause a fundamental characteristic of the task (e.g. data entry is tedious) or is it a characteristic of yourself (e.g. I'm terrified of public speaking)? Could something be done to change the emotional response? Should it? In this activity we ask students to very intentionally inspect the work and reflect on their response to it, rather than simply working.

In the second part of the learning plan, students complete research on their industry or sector of interest, including finding example positions in that industry and identifying required competencies.

Finally, in the third part of the exercise, students combine their findings about how they like to work and their industry research by writing an action plan for their final academic terms and their transition into the workforce. Students write both a primary and a backup plan to encourage broader thinking and avoid becoming stuck in one path. After giving an overview of each plan, they reflect on how well the plan matches their preferences of how and in what area they want to work, as well as assessing their readiness for the plan in terms of resources and confidence. Students list the actions they will take, including how they may close any skill gaps they previously identified from industry research, or how they can work to maximize the match between how they want to work and their initial prospects.

\subsection{Impact of engineering}

The third category of assignments deals with the GA selected for the course, the impact of engineering on 
society and the environment. The CEAB's definition of this attribute lists six major aspects (or groups of aspects) of society and the environment [3]. Therefore, the instructional portion of the course was divided into six units:

1. Health and Safety: The engineer's responsibility for the health and safety of society

2. Economy: Definition of engineering economics and how engineering and the economy influence one another

3. Law: Important legal considerations for practicing engineers

4. Culture: Empathy for others' viewpoints when working internationally or domestically with people of different backgrounds, including Indigenous Peoples of Canada

5. Environment: Roles of the engineer in environmental stewardship

6. Sustainability: Social, economic and environmental aspects of sustainable development and design

Each unit was developed by asking, "What relevant attributes (knowledge, skills, experiences and attitudes/beliefs) [8, 4] should a student have upon completion of the unit?" Development centered around a single, central attitude (or belief) about the topic of the unit that the impact of engineering SME understood to be held by m most successful engineers. It is one thing for a student to know their obligations as a future professional engineer, but it is quite another thing to believe in them.

Everything presented to or asked of the student in each unit is aligned to support the internalization of the associated belief. The "experience" in each unit is provided by one or two case studies. The student's active engagement with, and reflection on, these case studies is required to provide a meaningful experience which reinforces the importance of holding the associated belief as an engineer. The lessons in each unit provide the students with the requisite knowledge needed, and give them an opportunity to practice the skills necessary, for them to engage fully with the case studies. This allows for organization and prioritization of the course content in a way that supports the chosen attitude or belief attribute. If a content item was found to be interesting, but not necessary or not in alignment with the objective belief, it was excluded in the interest of streamlining the course. This method also allows for constructive alignment of the course outcomes, activities and assessments [1].

Students are meant to progress through each unit as shown graphically in Fig. 1. Figure 1 shows the attribute map for Unit 1: Health and Safety as an example, but the attribute maps for all units look similar. Students begin the unit with an assessment of their current beliefs about the relationship between the unit's topic and engineering. A multiple choice question with five options is asked. One of the options is the attitude that most professional engineers would acknowledge as most appropriate while the other choices include partial commitments, common misconceptions and even over-statements, such as "engineers are the only professionals responsible for the health and safety of the public". Many of the distractor answers are often explicitly disproven by the material in the units, especially common misconceptions. The

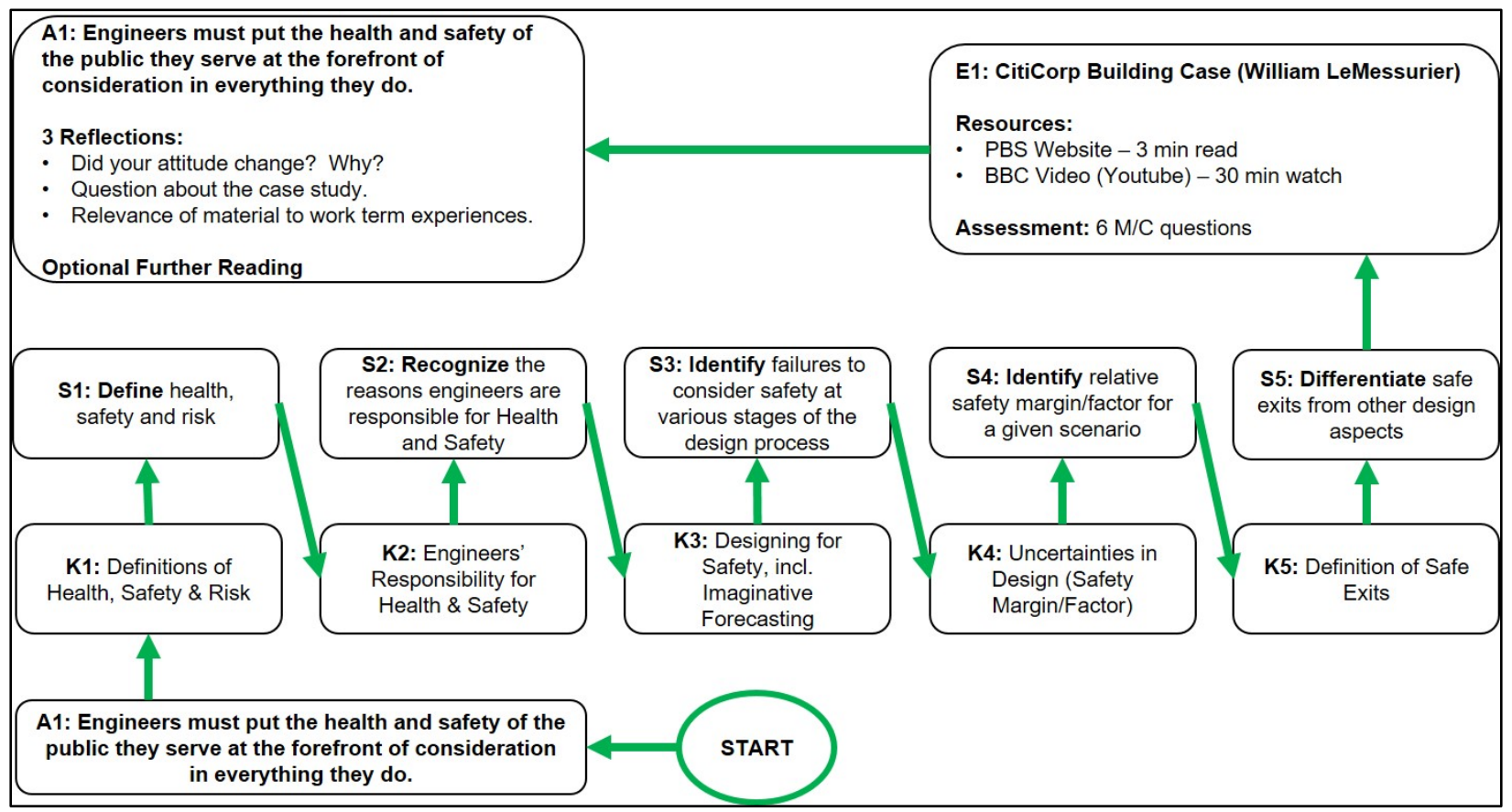

Fig. 1 A diagrammatic representation of how the student progresses through each unit's knowledge (K), skill (S), experience $(E)$ and attitude/belief (A) elements. The example shown is for Unit 1: Health and Safety. 
student's answer is logged for reflection later in the unit.

Students then begin a lesson which alternates between knowledge and skill elements as shown in Fig. 2. The scope of each knowledge element is defined by what is required for the student to practice the related skill; no more, no less. The facts, concepts and definitions which make up each knowledge element are most commonly transmitted through readings, but videos were included where possible. The development team determined that narrated slides or custom lecture videos would be more engaging, but these were not possible given the project budget. Furthermore, given the contract nature of the course development work in this particular case, finalized videos would make future revision of the content much more difficult once the impact of engineering SME had moved on. Creation of such materials is certainly an option that can be explored for future offerings of the course.

After each knowledge element, students advance to practice the related skill(s). The skill elements use action verbs such as "define" or "identify" so that they can be clearly assessed. The questions asked in these elements are not "for marks", but are very similar to the types of questions that are asked in the following case study, giving students a risk-free environment to practice the skills necessary for active engagement with the case study. Question types are predominantly multiple choice, but also include fill-in-the-blank, true/false and graphical matching questions. These practice questions are usually factual (recall) or require analysis of a very short (real or hypothetical) scenario. Students are given multiple attempts to answer each question with hints given after each incorrect answer and a detailed explanation once the correct answer is submitted. These hints and explanations form an important part the content delivery of the course, but are more interactive than the knowledge elements.

Once the student has advanced through all of the knowledge and skill elements of the lesson, they begin the experience: the case study. The case studies were carefully chosen to clearly support the goal attitude and even refute other beliefs. This often required two smaller case studies. For example, in Unit 2: Economy, the Toyota Prius was used as an example of how engineering decisions can affect the economy, while the Ford Pinto was used as an example of how economic considerations can impact engineering decisions. These two cases are contrasted to support the belief that decisions made by professional engineers are both subject to, and have an effect upon, the economy. There is certainly a long list of case studies that could be used, so for each unit the list was narrowed by considering factors such as the time required for students to fully engage with the case, the resources available to convey the facts of the case, and the impact of engineering SME's familiarity with the specifics of the case.

While students read or watch videos to cover the facts of each case study, active engagement is facilitated through the questions asked after the facts are covered. The questions mirror the types of questions practiced in the skill elements, but are now focused on the facts of the presented case study. For example, in Unit 6: Sustainability, students practice categorizing elements of a company's triplebottom-line accounting sheet, with feedback and enhanced explanations, as part of the unit's lesson. They are then asked to do so again for a less obvious example in the case study. The student's performance on the case study quiz determines their mark for the unit.

It can be very difficult to adequately assess such subjective material through these types of short answer questions, but relatively difficult questions can be asked simply because the student has had a chance to practice a very similar question and has received feedback on their answers. Furthermore, the questions often build on each other and gain complexity as the student progresses. This is achieved by giving the student multiple chances to answer each question, with possible marks diminishing with each incorrect answer. In this way, the student knows the correct answer (and sometimes are given a short explanation) before advancing, so an understanding of the correct answer can be assumed and integrated into the next question.

All students progress through the same assessment questions for the unit. A randomized bank of questions with algorithmically modified factors would be a great future enhancement of the course and would help to prevent cheating, but this represents a great deal of work for such subjective topics and was not possible within the constraints of the project budget.

Upon completion of the case study, the student is once again presented with the multiple choice question with which the unit began, asking them about their belief now that they have completed the unit. Comparison of the student's pre-course answer and post-course answer can be used to determine if the course is having the intended effect of actually changing students' beliefs. The student is also asked to reflect on whether or not their belief changed as a result of completing the unit and why, and how the content of the unit relates to their current work term.

After submitting these reflections, students are taken to an opinion poll related to the specifics of the case study. After logging their opinion, the student can see the responses of the class as a whole to compare their views with their peers. Students are then required to participate in a discussion forum based on a question again related to the case study. Students must both post a reply to the question, and comment on another student's post.

These discussion forums will be moderated by the course teaching assistant (TA), who will also be responsible for marking two of each student's contributions, chosen at random over the six units. The first contribution that is marked will come from one of the first three units, and students will be able to see the TA's feedback to help guide their future contributions. The second will come from one of the last three units, but the 
mark and any comments will not be visible until the end of the course, to help ensure students remain engaged with the activity. Marking will be done on a simple five-point rubric, based on the students' understanding of and engagement with the unit material.

Finally, students are directed to a list of optional further readings. That list includes many of the "nice, but not necessary" knowledge items which were excluded during the prioritization of content.

\subsection{Writing Exercises}

The final category of assignments consist of two writing exercises. These serve both to additionally assess the students' understanding of the impact of engineering units, and to help the students develop technical writing skills. The exercises were developed in collaboration by the impact of engineering and technical writing SMEs. This helped to ensure consistency with written assignments with which the students are familiar, especially in terms of document formats requested and grading rubrics.

The first writing assignment is to be completed after Unit 4: Culture. The student is presented with a scenario describing a major engineering project, and is asked to write a $\sim 400$ word memo to a hypothetical supervisor, identifying and categorizing stakeholders in the project, as well as outlining a brief stakeholder engagement strategy for the stakeholders deemed to be most important by the student.

The second writing assignment is completed after Unit 6: Sustainability, very near the end of the course. The students are again presented with a scenario, this time describing a problem facing a community, and asked to write $\mathrm{a} \sim 400$ word business letter which includes a problem definition statement to be presented to an engineering consulting firm. The students are asked to apply critical thinking to see past the problem presented and determine if there is an underlying problem which may have a truly sustainable solution.

These assignments will be marked by the course TA. A rubric was developed by the impact of engineering and technical writing SMEs to assess format and layout, content, and style and expression. The mark division between these elements is roughly $25 \%-50 \%-25 \%$.

\section{PILOT OFFERING}

As the course neared the end of its development period, planning for the pilot offering began. The Accreditation Analyst took on the role of course coordinator for the pilot. Parts of the duties of this position include the hiring and supervision of a TA for the course. The TA's role, budgeted at 100 hours over the four-month term, includes marking discussion board contributions and the writing assignments (as shown in Table 1), as well as moderating the discussion forums and communicating with students.
The TA is also required to collect information over the term that will help us evaluate the pilot: records of questions asked by students and a breakdown of how many hours are spent marking, moderating and communicating. This will be supplemented by an exit interview with the course coordinator to discuss the overall success of pilot, which aspects worked particularly well, and which aspects need to be changed.

The position was advertised in both the Faculty of Engineering and the Department of English, and ultimately an English masters students was selected for the role. Although an engineering student may have been better able to relate to the pilot participants, and may have had more knowledge and background experience in the topic of the impact of engineering, it was felt that it was more important to hire a person with strong skills and experience in marking non-technical writing and reflections.

The Co-op office selected 59 students who would be on work term in Summer 2019 to participate in the pilot. The students were selected from among those completing one of their final work terms, in order to ensure the pilot participants were already familiar with the co-op process and would be able to compare the new format with the existing format. Students from all six undergraduate engineering programs at UVic were included, as well as a few students from the undergraduate computer science program (also offered through the Faculty of Engineering at UVic), and our course-based Master of Engineering graduate program. Although the course was not designed with these last two groups in mind, the Co-op office was interested to see how the course would work for these students. When the full four-course program is implemented, it would be much simpler for the co-op office if all Faculty of Engineering co-op students could participate.

The pilot participants were emailed approximately three weeks before the start of the summer term to inform them they would be participating in the pilot and provide some preliminary information. Students were encouraged to contact the course coordinator with any questions or concerns; approximately $10 \%$ of students did so, including two who expressed desire to be removed from the pilot. The course coordinator communicated further with these students, and at the time of writing, all selected pilot participants are still enrolled in the course.

UVic co-op students are always assigned a Work Site Visit (WSV) Coordinator who is their main point of contact during a work term. The co-op office decided to distribute the 59 pilot students among 10 different WSV coordinators. The course coordinator met with the group to provide background on the pilot and review the assignments they would be responsible for marking: the competency assessment and the learning plan. The WSV coordinators were also asked to keep records of the questions students ask and the time required to mark their components of the course. The course coordinator will 
meet again with the WSV coordinator team at two points during the term and after the pilot is completed to get their overall impressions.

\section{NEXT STEPS}

As of the submission of this paper, the Summer 2019 pilot course had just opened. The course coordinator will be monitoring the progress of the course closely, through communication with the TA and the WSV coordinators, as well as through usage data provided by our LMS.

In addition to this information and the records and feedback provided by the TA and WSV coordinators at the end of term, we will also assess the pilot on the basis of an exit survey for pilot participants. This survey will ask questions about students' perceptions of the workload of the course and its impact and relevance to their education and careers. A matched group of students who did not participate in the pilot will be given a similar survey so responses can be compared.

Careful analysis of this assessment data will allow us to determine if and how the project should proceed. Assuming the project does continue, our hope is that development of future courses will be somewhat simpler: the overall structure of the course can be re-used, as can the redesigned competency assessment exercise.

However, we will need to address a number of issues as we move forward. First is the workload of the course, and relatedly, the relative weightings of the various components. Were our time estimates for each assignment accurate? Are we happy with the division of time and marks between the different categories of assignments?

Issues we identified in our previous paper are also still outstanding: how to assign a numeric grade to the course; how to implement the rollout of the full set of four courses; how to communicate the nature and motivation for the changes to students, faculty and employers; and how to measure the effects of this change on our programs.

Finally, as always, the issue of funding must be considered. After developing the first course, we now have a better estimate of development costs, and are pursuing grants through the university's Learning and Teaching Support and Innovation office that would help to cover these.

As for ongoing costs, results from the pilot will help us answer important questions about personnel requirements: how many TA hours are required per student? How much work is the course coordinator role, and what kind of qualifications are necessary for this role? Armed with these answers, we hope to be able to secure the permanent funding that will allow this project to come to fruition.

\section{Acknowledgements}

The authors wish to acknowledge Rebecca Edwards and Derek Murray from TIL, without whom this course would not exist. They also wish to acknowledge Suzan Last and
Monika Smith, our technical writing experts from the Department of English, and the other three members of the co-op SME team: Cheryl Beaumont, Susan Fiddler and Ahmad Salman.

\section{References}

[1] John Biggs, "Enhancing teaching through constructive alignment," Higher Education, vol. 32, no. 3, pp. 347364, 1996.

[2] Bill Burnett and Dale Evans, Designing Your Life. New York: Alfred A. Knopf, 2016, 272 pp.

[3] Canadian Engineering Accreditation Board, 2018 Accreditation Criteria and Procedures. Ottawa, ON: Engineers Canada, 2018, 128 pp. Available as of May 4, 2019 from https://engineerscanada.ca/sites/default/ files/accreditation/Accreditation-criteria-procedures2018.pdf

[4] Joel B. Frey, Sean Maw, Susan Bens, and Bruce Sparling, "Design of a Completely New First Year Engineering Program at the University of Saskatchewan," Proc. CEEA Canadian Engineering Education Conf. (Vancouver, BC; 3-6 June 2018), 8 pp, 2018. Available as of May 4, 2019 from https://doi.org/10.24908/pceea.v0i0.13091

[5] Margaret Gwyn, "Find the GAPs: The development of a network for graduate attribute professionals", Proc. CEEA Canadian Engineering Education Conf. (Toronto, ON; 4-7 June 2017), 4 pp, 2017. Available as of May 4, 2019 from https://doi.org/10.24908/pceea.v0i0.10302

[6] Ontario Society of Professional Engineers, Crisis in Ontario's Engineering Labour Market. Toronto, ON: 2015, 24 pp. Available as of May 4, 2019 from www.ospe.on.ca/public/documents/advocacy/2015crisis-in-engineering-labour-market.pdf

[7] Bryson Robertson, Margaret Gwyn, LillAnne Jackson, and Peter Wild, "Three birds, one stone: A pedagogy and accreditation driven redesign of co-op work term requirements", Proc. CEEA Canadian Engineering Education Conf. (Vancouver, BC; 3-6 June 2018), 5 pp, 2018. Available as of May 4, 2019 from https://doi.org/10.24908/pceea.v0i0.13055

[8] Armando Rugarcia, Richard M. Felder, Donald R. Woods and James E. Stice, "The future of engineering education I. a vision for a new century," Chem. Engr. Education, vol. 34, no. 1, pp. 16-25, 2000.

[9] Benjamin Tal, The Haves and Have Nots of Canada's Labour Market. Toronto, ON, CIBC, 2012, 5 pp. Available as of May 4, 2019 from en.copian.ca/library/ research/cibc/haves_have_nots/haves_have_nots.pdf

[10] Technology Integrated Learning, Blueprinting your course. Victoria, BC: University of Victoria, 2017. Available as of May 4, 2019 from https://onlineacademiccommunity.uvic.ca/learnteachte ch/2017/09/11/blueprinting-your-course 